\title{
Notable shifting in the responses of vegetation activity to climate change in China
}

\author{
Aifang Chen ${ }^{a}$, Bin He ${ }^{\mathrm{a}, \mathrm{b}, *}$, Honglin Wang ${ }^{\mathrm{a}}$, Ling Huang ${ }^{\mathrm{a}}$, Yunhua $\mathrm{Zhu}^{\mathrm{c}}$, Aifeng $\mathrm{Lv}^{\mathrm{d}}$ \\ ${ }^{a}$ College of Global Change and Earth System Science, Beijing Normal University, Beijing 100875, China \\ b Joint Center for Global Change Studies, Beijing 100875, China \\ ' College of Business Administration, Huaqiao University, Fujian 362021, China \\ ${ }^{\mathrm{d}}$ Institute of Geographic Sciences and Natural Resources Research, Chinese Academy of Sciences, Beijing 100101, China
}

\section{A R T I C L E I N F O}

\section{Article history:}

Received 31 March 2015

Received in revised form 29 July 2015

Accepted 24 August 2015

Available online 4 September 2015

\section{Keywords:}

Pearson correlation

NDVI

Climate change

China

\begin{abstract}
A B S T R A C T
The weakening relationship between inter-annual temperature variability and vegetation activity in the Northern Hemisphere over the last three decades has been reported by a recent study. However, how and to what extent vegetation activity responds to climate change in China is still unclear. We applied the Pearson correlation and partial correlation methods with a moving 15-y window to the GIMMS NDVI dataset from NOAA/AVHRR and observed climate data to examine the variation in the relationships between vegetation activity and climate variables. Results showed that there was an expanding negative response of vegetation growth to climate warming and a positive role of precipitation. The change patterns between NDVI and climate variables over vegetation types during the past three decades pointed an expending negative correlation between NDVI and temperature and a positive role of precipitation over most of the vegetation types (meadow, grassland, shrub, desert, cropland, and forest). Specifically, correlation between NDVI and temperature $\left(P_{\mathrm{NDVI}-\mathrm{T}}\right)$ have shifted from positive to negative in most of the station of temperature-limited areas with evergreen broadleaf forests, whereas precipitationlimited temperate grassland and desert were characterized by a positive $P_{\text {NDVI-P. }}$ This study contributes to ongoing investigations of the effects of climate change on vegetation activity. It is also of great importance for designing forest management strategies to cope with climate change.
\end{abstract}

๑) 2015 Elsevier Ltd. All rights reserved.

\section{Introduction}

Currently, the most challenging global environmental problem is climate change, as evidenced by rapid global warming and the increasing frequency of extreme climate events. Climate change can significantly affect vegetation activity (Myneni et al., 1997; Piao, 2003; Badeck et al., 2004; Garrity et al., 2011; Peng et al., 2011; Chen and Chen, 2013; Wu and Liu, 2013) and influence the terrestrial carbon cycle. Previous studies have reported both positive and negative influences of climate change on vegetation growth. For example, the observed increase in vegetation growth over the past several decades in the Northern Hemisphere was partly attributed to significant warming (Zhou et al., 2001), while as the increasing frequency of climate-driven extreme events, such as drought, was shown to possibly convert terrestrial ecosystems from carbon sinks to sources by constraining vegetation growth (Reichstein et al., 2013). Considering the great ecological

* Corresponding author at: College of Global Change and Earth System Science, Beijing Normal University, and Joint Center for Global Change Studies, Beijing 100875, China.

E-mail address: hebin@bnu.edu.cn (B. He). importance of vegetation, which provides habitat for millions of species on Earth, either directly through plants or indirectly through animals or microbes that feed on plants via predation, parasitism, or decomposition (Alcamo et al., 2003), it is crucial to monitor and assess the response of vegetation to climate change.

The study of the response of vegetation growth to climate change on regional, continental, and global scales is receiving increasing attention (Myneni et al., 1997; Zhou et al., 2001; Lucht et al., 2002; Piao, 2003; Piao et al., 2006a, 2014; Anderson et al., 2010; Peng et al., 2011; Wu et al., 2012). Recent research has indicated a weakening relationship between inter-annual temperature variability and northern vegetation activity over the past three decades (Piao et al., 2014). However, how and to what extent the response of vegetation growth to climate variables has changed in China is still unclear.

Over the past three decades, vegetation growth has increased during the growing season in China (Peng et al., 2011; Xu et al., 2014), and climate change is a leading cause of this phenomenon. Consistent warming is considered to be a main driving force on vegetation growth in China, especially in southern China, where vegetation growth is limited by temperature. In northern China, 
where vegetation growth is limited by water, precipitation is the leading factor for vegetation growth. Before the 2000s, vegetation growth in this region was stimulated by increased precipitation, however, this increase was undermined by expanding drought in the last decade over northern China (Xu et al., 2012). Other factors, such as $\mathrm{CO}_{2}$ fertilization, ecological protection, restoration, and increasing solar radiation, are also responsible for increasing vegetation growth in China (Peng et al., 2011; Xu et al., 2012). The correlation between the satellite-derived normalized difference vegetation index (NDVI) and climate variables has been shown to be spatially heterogeneous (Wang et al., 2003; Zhang et al., 2013; $\mathrm{Xu}$ et al., 2014). However, the link between climate change and vegetation growth in China, especially variations in these correlations, has not been adequately quantified.

The NDVI is an effective indicator of vegetation greenness (Zhou et al., 2001; Tucker et al., 2005; Xu et al., 2012; Liu et al., 2013, 2014), and it has been frequently used to portray temporal and spatial changes in vegetation activity (Myneni et al., 1997; Zhou et al., 2001, 2003; Ji and Peters, 2003; Liu et al., 2014). The newly issued Global Inventory Modeling and Mapping Studies (GIMMS) NDVI dataset (Tucker et al., 2005) from NOAA/AVHRR, covering the period from 1982 to 2011, allowed us to investigate long-term vegetation activity. The goal of this study was to assess the variation in the relationships between NDVI and climate variables from 1982 to 2011 by employing the Pearson correlation and partial correlation methods with 15-y moving windows to the GIMMS NDVI datasets and corresponding station-based meteorological datasets.

\section{Data and methods}

\subsection{NDVI data}

We used the latest version of GIMMS NDVI dataset from NOAA/AVHRR with a spatial resolution of $0.083^{\circ}$ and 15 -d interval over the period from 1982 to 2011. To avoid the influence of nongrowing season data, during which the NDVI may be affected by non-vegetated areas and bare soil, we confined the investigation period to the growing season (from April to October) (Zhou et al., 2001; Peng et al., 2011; Piao et al., 2011). The raw NDVI dataset was processed as follows. First, pixels with an average NDVI from April to October less than 0.05 were considered as non-vegetated areas and removed from the study to minimize the impact of soil variations in bare and sparsely vegetated regions (Zhou et al., 2001; Peng et al., 2011; Piao et al., 2011). To further reduce residual cloud contamination, atmospheric, and bidirectional effects, we produced a monthly NDVI dataset using the maximum value composite (MVC) method to obtained monthly NDVI (Holben, 1986; Piao, 2003; Fang, 2004; Peng et al., 2011), which were averaged with the growing season NDVI for further analyses. The bilinear interpolation method was used to extract the NDVI values corresponding to the station data based on grid vegetation data with a spatial resolution of $0.083^{\circ}$ (Vu et al., 2012). Finally, monthly NDVI sequence data, corresponding to select climate stations in China and spanning the period from 1982 to 2011, were generated.

\subsection{Meteorological data}

The station-based climate data from 1982 to 2011, including temperature and precipitation, were obtained from China's Meteorological Data Sharing Service System website (http://cdc. nmic.cn/home.do). This dataset was quality controlled prior to being published. To produce the growing season climate data, basic monthly temperature data was downloaded and averaged from April to October of each year, and the precipitation data was evaluated as the sum of the monthly precipitation over this period. The climate data from 518 out of 726 meteorological stations, which were of high quality and covered the study period, were used in the analysis. The other 208 stations were excluded owing to poor qualifications such as missing data during growing season.

\subsection{Vegetation types}

Ecosystem distribution in China is controlled by climate (Chen and Chen, 2013). For the purpose of investigating changes in vegetation response to climate variables in different biomes, this analysis was based on the vegetation maps with a scale of $1: 1,000,000$ from the Atlas of China's Vegetation. All biomes were classified into seven types: forest, shrub, grassland, cropland, meadow, desert and others (Zhao et al., 2011) (Fig. 1). And for better understanding the response of vegetation to climate change, we separated China into two parts, north China and south China, according to the map of Chinese North-South demarcation zone (Tan, 2011).

\subsection{Methodology}

The relationships between NDVI and temperature and precipitation were examined on national scale and at individual station using Pearson correlation analysis (Pearson correlation coefficients of NDVI and temperature and precipitation were abbreviated as $P_{\text {NDVI-T }}$ and $P_{\text {NDVI-P, }}$ respectively). To examine these relationships on a national scale, each of the three variables obtained from the 518 stations were averaged together.

For the purpose of portraying the correlations of NDVI with temperature and precipitation, we applied the linear detrending method to produce the anomalies, or residuals, associated with internally driven climate phenomena. Then, we interpreted the time series of the residuals of NDVI, temperature, and precipitation, respectively (Piao et al., 2014). As vegetation variables are influenced by several factors (e.g., temperature, precipitation, cloud cover, solar radiation, anthropogenic activity, etc.), partial correlation analyses were also conducted to study the apparent responses of NDVI to temperature and precipitation, with the intention of eliminating the covariate effects of other factors.

More precisely, both Pearson correlation and partial correlation analyses were performed to analyze the correlations of NDVI with mean growing season temperature and total growing season precipitation with a 15-y moving window (Piao et al., 2014). The correlation of NDVI and climate variables can be influenced by general changes in background climate over a period of 15 years (Piao et al., 2014). For example, the correlations of NDVI with temperature and precipitation were calculated in the first 15-y window (1982-1996). The window then moved forward 1 year to represent the second 15-y window (1983-1997), and so on until the last 15-y window. In this way, we described the changes in vegetation growth responses to climate variability from 1982 to 2011. Pearson correlations over 9-year and 19-year moving windows were also investigated to avoid the influence of window width. The data processing and calculations were conducted with the Interactive Data Language (IDL) program, ArcGIS10.1 software, SPSS, and R software.

\section{Results}

3.1. Trends of national inter-annual changes of vegetation and climate variables

Inter-annual changes in China's annual NDVI, temperature, and precipitation from 1982 to 2011 were revealed in Fig. 2. 


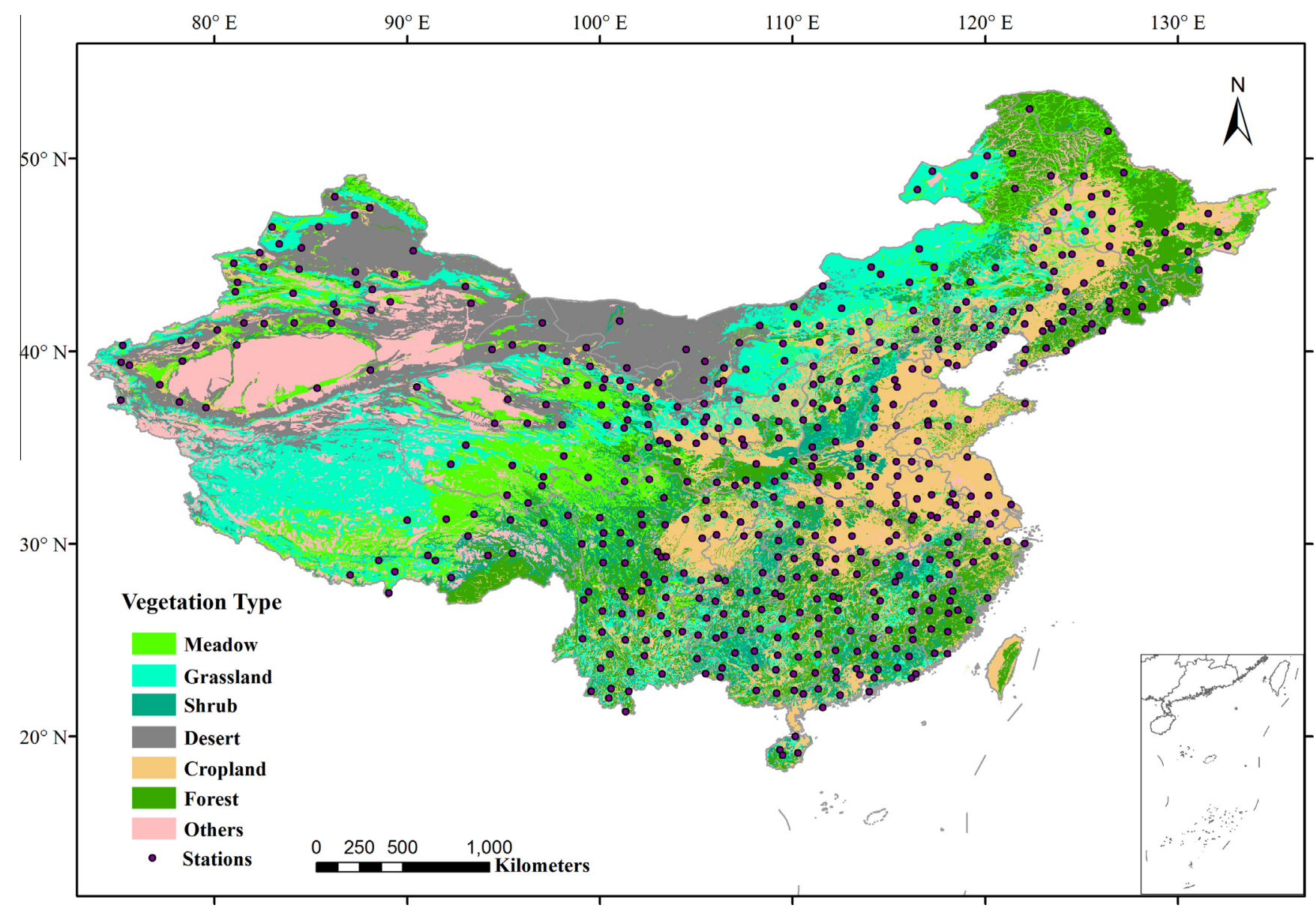

Fig. 1. Spatial distribution of studied vegetation type and selected climate stations across China, including meadow, grassland, shrub, desert, cropland, forest and others.

Throughout China as a whole, the NDVI significantly increased $(p<0.01)$ over the 30 -year study period. The NDVI steadily increased before the late 2000s, then decreased dramatically, and finally surged quickly after 2005 (Fig. 2A). Temperature also significantly increased over the 30-year period $(p<0.01)$, rising by $0.74{ }^{\circ} \mathrm{C}$ at a rate of $0.025^{\circ} \mathrm{C} /$ year (Fig. 2B). In contrast, precipitation decreased weakly over the past three decades (Fig. 2C).

\subsection{Tendencies of correlations between national NDVI and climate variables}

The nation-wide responses of NDVI to temperature and precipitation were analyzed with Pearson correlations (Fig. 3A). It is interesting to find that the correlation coefficients between NDVI and temperature $\left(P_{\mathrm{NDVI}-\mathrm{T}}\right)$ shifted from positive values in the early $15-\mathrm{y}$ windows to negative correlations in the later windows, which occurred over the period from 1985 to 1999. As to the correlation between NDVI and precipitation $\left(P_{\text {NDVI-P }}\right)$, it experienced consistently positive values throughout the study period, though the values fluctuated. The magnitude of $P_{\text {NDVI-P }}$ decreased in the early $15-\mathrm{y}$ windows, but rebounded in the later. The value of $P_{\mathrm{NDVI}-\mathrm{T}}$ was positive $(0.56 ; p<0.05)$ during the first 15 years, but was negative $(-0.36 ; p=0.19)$ during the last 15 years, however, it exhibited weak variations on the value of $P_{\mathrm{NDVI}}$. . The variations in $P_{\text {NDVI-P }}$ and $P_{\text {NDVI-T }}$ calculated based on 9-year and 19-year moving windows (Figs. S1 and S2) were similar to those based on 15-y windows, suggesting that the width of the moving windows did not affect the trends.
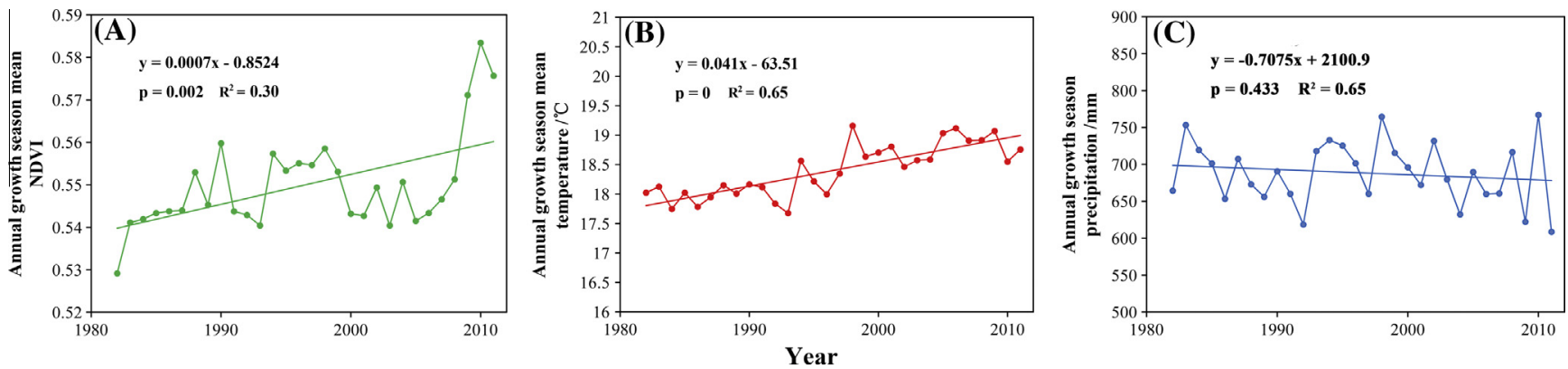

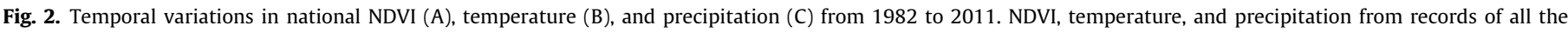
observation stations in China were averaged over each year. The solid lines represent linear regressions. 

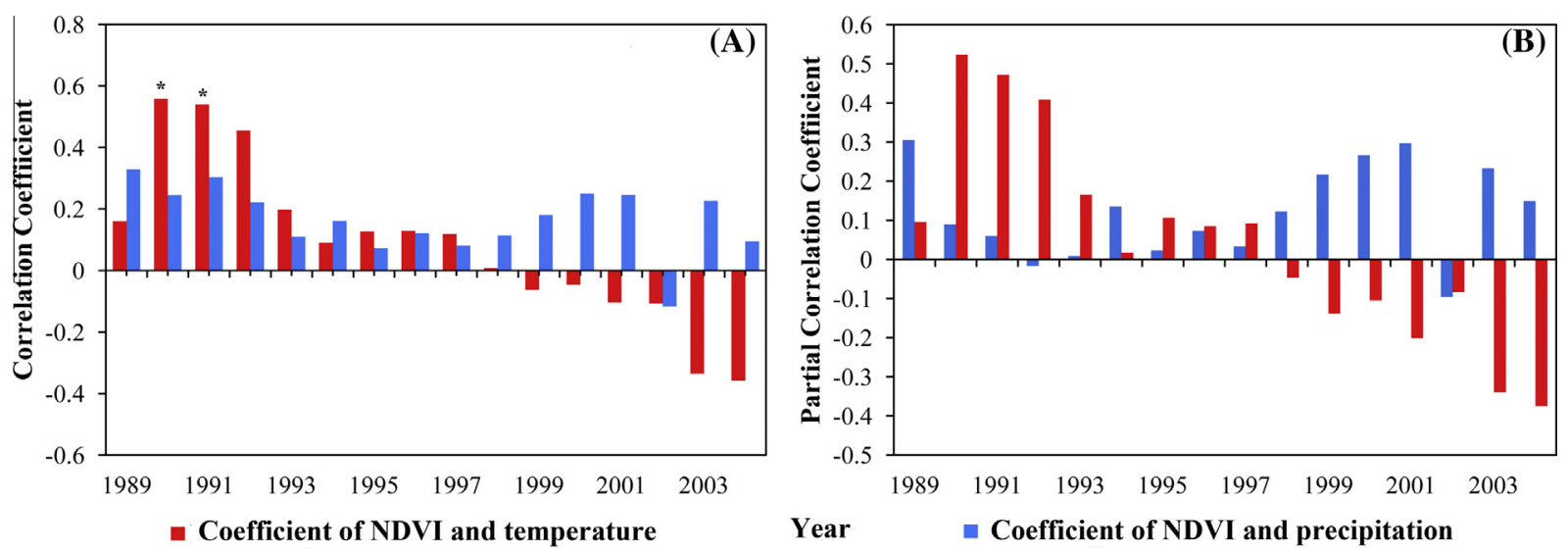

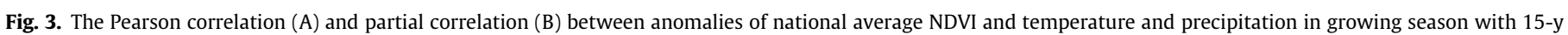
moving windows, respectively. Correlations with $p$-values $<0.05$ are marked with an asterisk.

To further investigate the responses of NDVI to temperature and precipitation, partial correlation analyses were performed between the detrended NDVI and climate variables with 15-y moving windows to remove the mutual influences of temperature and precipitation, as shown in Fig. 3B. Variations in correlation coefficient were similar to those of the Pearson correlations, but with smaller magnitudes. This analysis further validated the great change in the relationship between temperature and NDVI, and the small change in the relationship between precipitation and NDVI.

\subsection{Spatial pattern of tendencies of correlations between NDVI and climate variables}

The spatial variations in correlations between vegetation activity and climate variables over 30 years were summarized in Fig. 4. The Pearson correlation coefficients, $P_{\mathrm{NDVI}-\mathrm{T}}$ and $P_{\mathrm{NDVI}-\mathrm{P}}$, varied greatly among the stations, suggesting large differences in the response of vegetation type to climate change throughout China. Generally, about $65 \%$ of stations displayed continuous negative or changing from positive to negative $P_{\mathrm{NDVI}-\mathrm{T}}$ in this time periods; while approximately $58 \%$ stations revealed opposite patterns in $P_{\text {NDVI-P. }}$ And the value of $P_{\mathrm{NDVI}-\mathrm{T}}$ which changes from positive to negative was $30 \%$, as the opposite correlations of $P_{\text {NDVI-T }}$ was $18 \%$, though the counterpart in $P_{\text {NDVI-P }}$ revealed similar pattern, the difference between those two were not significant, which was coherent to the national pattern, indicating an expanding negative response of vegetation growth to climate warming and a positive role of precipitation.

Specifically, over $72 \%$ of the north China stations showed continuous negative or changing from positive to negative $P_{\text {NDVI-T }}$, which were mainly located in temperate grasslands and desert areas; however, most of these stations were usually with positive correlation between NDVI and precipitation, suggesting precipitation was the main factor limiting vegetation growth in these areas. In south China, stations with negative and those with positive $P_{\text {NDVI-T }}$ (or $P_{\text {NDVI-P }}$ ) were of similar number, which took up to $59 \%$ and $41 \%$ (56\% and $44 \%$ ). But it was necessary to note that $39 \%$ stations were with $P_{\mathrm{NDVI}-\mathrm{T}}$ changing from positive to negative, suggesting a notable shifting response of vegetation activity to climate warming in this region where were mostly covered by evergreen broadleaf forest and typically temperature-limited growth areas according to previous knowledge.

The change patterns of relationships between NDVI and climate variables over vegetation types during the past three decades were shown in Fig. 5. Negative $P_{\mathrm{NDVI}} \mathrm{T}$ accounted for the largest percentages over the six vegetation types (meadow, grassland, shrub, desert, cropland, and forest) (Fig. 5A). There were about $50 \%$ of stations in grassland and desert characterized by continuous negative $P_{\text {NDVI-T }}$ and approximately $30 \%$ of stations with $P_{\text {NDVI-T }}$ changed from positive to negative in grassland, shrub, cropland and forest;
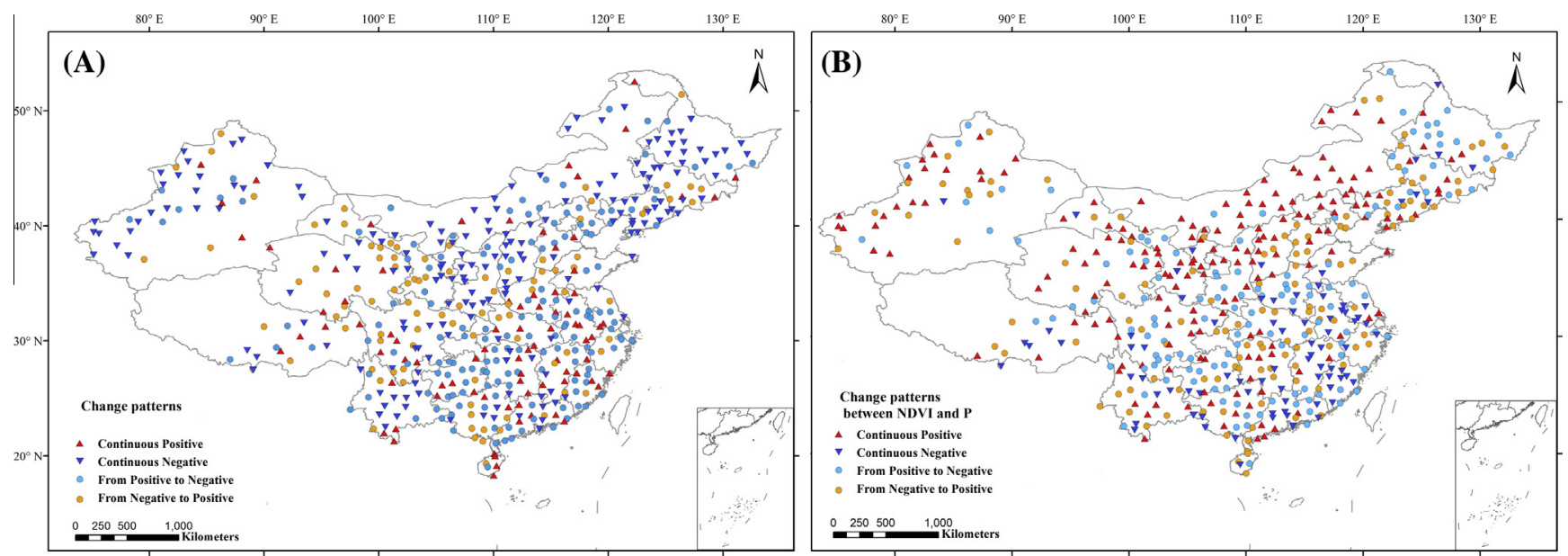

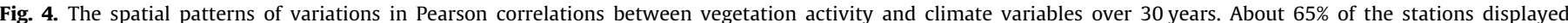

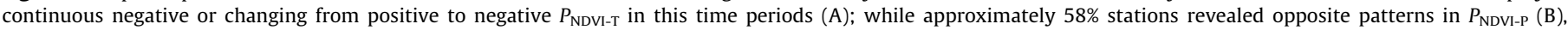
indicating a negative response of vegetation to climate warming and a positive role of precipitation. 


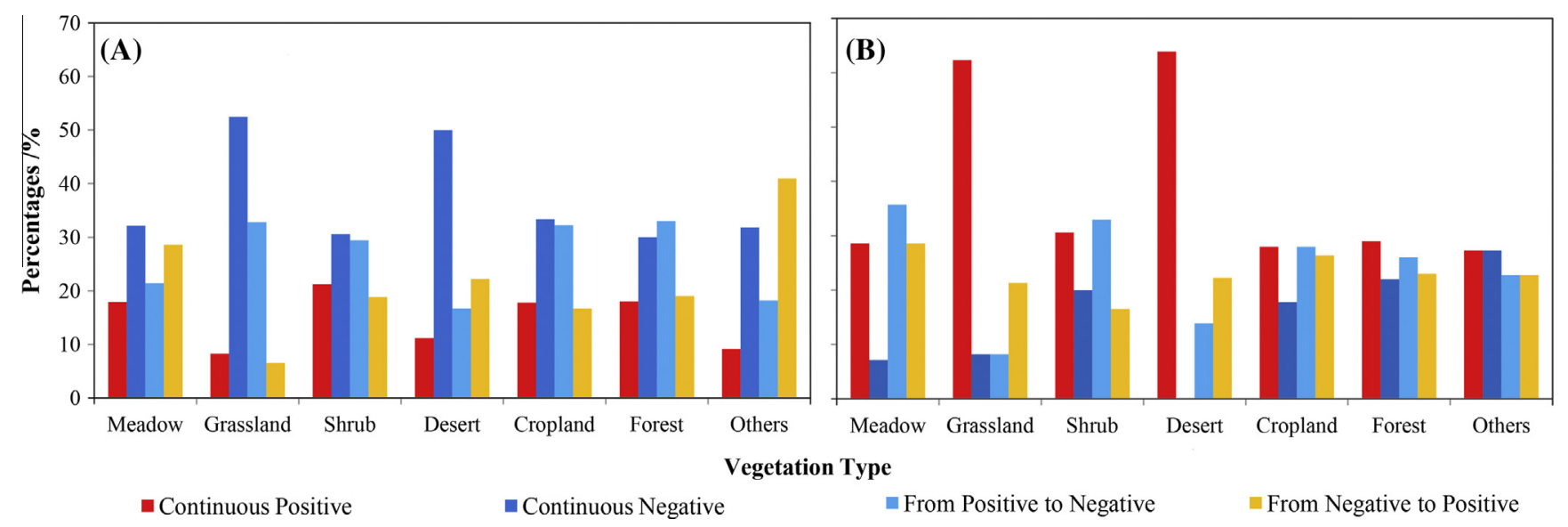

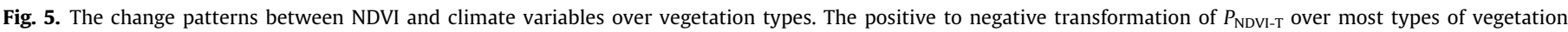

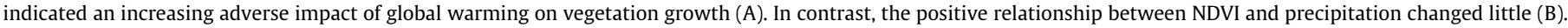

whereas the stations with the opposite $P_{\text {NDVI-T }}$ changed from negative to positive were equal to $20 \%$ in these vegetation types except meadow and the others. The positive $P_{\mathrm{NDVI}}$-P held highest percentages over most vegetation types (Fig. 5B) in China, and over $60 \%$ of stations with continuous positive correlation coefficients were founded in grassland and desert. Unlikely to the variation of $P_{\text {NDVI-T }}$, most of vegetation types shared about equal percentages of stations with $P_{\text {NDVI-P }}$ changed from positive to negative and the opposite one except grassland and desert. Over these two types, there were more stations with the correlation which changed from negative to positive. Generally speaking, the larger proportion of stations with continuous negative relationships of $P_{\text {NDVI-T }}$ or positive to negative transformations over most types of vegetation indicates increasing adverse impacts of climate warming on vegetation growth. Compared with $P_{\text {NDVI-T, }}$, more stations with positive relationships of $P_{\text {NDVI-P }}$ or relationships from negative to positive suggested a positive effect of precipitation on vegetation growth on national scale.

\section{Discussions}

Climate warming has greatly affected vegetation growth in China over the past three decades (Zhou et al., 2001; McMahon et al., 2010; Mao et al., 2012; Cong et al., 2013; Xu et al., 2014). According to this study, the positive relationship between temperature and NDVI became negative over the course of the study period, although this result was not statistically significant. However, this suggests that the positive effect of increasing temperature on vegetation growth diminished over time, and more seriously, climate warming appears to be harmful to vegetation growth. The shifting changes in $P_{\mathrm{NDVI}} \mathrm{T}$ mainly occurred in evergreen broadleaf forests, which are located in temperature-limited areas of south China, for the previous studies which warned of the potential change in the effects of climate warming on vegetation growth and claimed that higher temperature does not always increase vegetation growth (Wang et al., 2003; Wu et al., 2012; Fu et al., 2013; Zhang et al., 2013), it shall be an alert of the side effect of climate warming of vegetation activity. NDVI significantly decreased owing to experimental warming (Wu et al., 2012; Fu et al., 2013) and was negatively correlated to maximum temperature (Wang et al., 2003). Even more, Wu et al. (2012) found that warming altered the plant community in grassland ecosystem, causing encroachment by species typical of warmer environments and loss of species from the native environment.

As temperature has increased in China over the past three decades, the stimulation of vegetation growth due to temperature has gradually diminished, and the weakening positive impacts of climate warming on vegetation growth may be partly related to warming-induced soil drying (Trenberth et al., 2007; Piao et al., 2010, 2014; Dai, 2011; Peng et al., 2011; Fu et al., 2013) causing by increasing evaporation (Sun et al., 2013). Previous studies have suggested that although warming could enhance forest vegetation growth in South China (Peng et al., 2011), drought has become more common since the 1970s, especially in the tropics and subtropics, and the effect of drought can attenuate the response of NDVI to temperature (Piao et al., 2014).

On the contrary, over $70 \%$ of stations were positive in the correlation between NDVI and precipitation in north China, which mainly occurred in the precipitation-limited temperate grassland and desert where the vegetation growth is restricted by precipitation (Peng et al., 2011; Zhao et al., 2011). These areas are the driest regions of China, and the mean annual precipitation is usually below $400 \mathrm{~mm}$. Thus, the positive correlation between NDVI and precipitation in these regions is logical (Piao et al., 2006b). The decreasing Palmer Drought Severity Index (PDSI) in recent decades may intensify the drought stress in temperate grasslands (Cao et al., 2010, 2011), pointing a decreasing trend of the positive effect of precipitation on vegetation growth in recent years. In desert areas, the weakening contribution of precipitation may be offset by increases in ice and snow melting due to increasing temperature (Wang et al., 2010). This is because snow and glacier-fed river catchments in northwest China contribute to a major proportion of the river flow (Ma et al., 2013).

Other parameters such as cloud cover, $\mathrm{CO}_{2}$ concentration, and human activity may contribute to increasing vegetation growth (Piao et al., 2006b, 2014; Peng et al., 2011; Mao et al., 2012; Xu et al., 2012). The Qinghai-Tibet Plateau alpine meadow region was the most sensitive to climate change (Ding et al., 2007; Xu and Liu, 2007; Li et al., 2010; Zhang et al., 2013). Human activities, such as the "Green for Green" program, livestock overgrazing, and poor livestock management may also profoundly affect the vegetation growth in this areas (Zhang et al., 2013).

\section{Conclusions}

In conclusion, on national scale, the response of vegetation growth to temperature change in recent decades was positive in the beginning of the study period, but became negative in later years. However, the relationship between NDVI and precipitation did not change significantly. And the change patterns between NDVI and climate variables over vegetation types during the past three decades pointed an expending negative correlation between 
NDVI and temperature and a positive role of precipitation over most of the vegetation types (meadow, grassland, shrub, desert, cropland, and forest). Specifically, $P_{\text {NDVI-T }}$ have shifted from positive to negative in most of the station of temperature-limited areas with evergreen broadleaf forests, whereas precipitation-limited temperate grassland and desert were characterized by a positive $P_{\text {NDVI-P. }}$ The variations in the correlations of NDVI between temperature and precipitation suggest a weakening contribution of these two climate variables on national scale. Increasing vegetation growth may be due to other factors such as solar radiation, $\mathrm{CO}_{2}$ fertilizer, and human activities. The role of these factors calls for more intense surveillance and should be included in the future studies.

Results of this study enhance knowledge of complex relationships between climate and vegetation, which contributes to ongoing investigations of the effects of climate change on vegetation activity. It also can provide guidance for decision-makers for forest management and making policies for adaptations to climate change.

\section{Acknowledgements}

This work is financially supported by the National Natural Science Foundation of China (Grant no. 41301076) and the National Basic Research Development Program of China (Grant nos. 2011CB952001 and 2012CB95570001).

\section{Appendix A. Supplementary material}

Supplementary data associated with this article can be found, in the online version, at http://dx.doi.org/10.1016/j.pce.2015.08.008.

\section{References}

Alcamo, J., Ash, N.J., Butler, C.D., Callicott, J.B., Capistrano, D., Carpenter, S.R., Castilla J.C., Chambers, R., Chopra, K., Cropper, A., Daily, G.C., Dasgupta, P., Groot, R.d. Dietz, T., Duraiappah, A.K., Gadgil, M., Hamilton, K., Hassan, R., Lambin, E.F., Lebel, L., Leemans, R., Jiyuan, L., Malingreau, J.-P., May, R.M., McCalla, A.F., McMichael, T.A.J., Moldan, B., Mooney, H., Naeem, S., Nelson, G.C., Wen-Yuan, N., Noble, I., Zhiyun, O., Pagiola, S., Pauly, D., Percy, S., Pingali, P., Prescott-Allen, R. Reid, W.V., Ricketts, T.H., Samper, C., Scholes, R.B., Simons, H., Toth, F.L., Turpie, J.K., Watson, R.T., Wilbanks, T.J., Williams, M., Wood, S., Shidong, Z., Zurek, M.B. 2003. Ecosystems and Human Well-being: A Framework for Assessment Millennium Ecosystem Assessment. Island Press, Washington, Covelo, London.

Anderson, R.G., Canadell, J.G., Randerson, J.T., Jackson, R.B., Hungate, B.A., Baldocchi, D.D., Ban-Weiss, G.A., Bonan, G.B., Caldeira, K., Cao, L., Diffenbaugh, N.S., Gurney, K.R., Kueppers, L.M., Law, B.E., Luyssaert, S., O’Halloran, T.L., 2010. Biophysical considerations in forestry for climate protection. Front. Ecol. Environ. 9, 174182.

Badeck, F.-W., Bondeau, A., Bottcher, K., Doktor, D., Lucht, W., Schaber, J., Sitch, S. 2004. Responses of spring phenology to climate change. New Phytol. 162, 295 309.

Chen, D., Chen, H.W., 2013. Using the Köppen classification to quantify climate variation and change: an example for 1901-2010. Environ. Develop. 6, 69-79.

Cong, N., Wang, T., Nan, H., Ma, Y., Wang, X., Myneni, R.B., Piao, S., 2013. Changes in satellite-derived spring vegetation green-up date and its linkage to climate in China from 1982 to 2010: a multimethod analysis. Global Change Biol. 19, 881 891.

Dai, A., 2011. Characteristics and trends in various forms of the Palmer Drought Severity Index during 1900-2008. J. Geophys. Res., 116

Ding, M., Zhang, Y., Liu, L., Zhang, W., Wang, Z., Bai, W., 2007. The relationship between NDVI and precipitation on the Tibetan Plateau. J. Geogr. Sci. 17, 259268.

Fang, J., 2004. Increasing terrestrial vegetation activity in China, 1982-1999. Sci. China Series C 47, 229.

Fu, G., Zhang, X., Zhang, Y., Shi, P., Li, Y., Zhou, Y., Yang, P., Shen, Z., 2013. Experimental warming does not enhance gross primary production and aboveground biomass in the alpine meadow of Tibet. J. Appl. Remote Sensing 7 073505.

Garrity, S.R., Bohrer, G., Maurer, K.D., Mueller, K.L., Vogel, C.S., Curtis, P.S., 2011. A comparison of multiple phenology data sources for estimating seasonal transitions in deciduous forest carbon exchange. Agric. For. Meteorol. 151, $1741-1752$.

Holben, B.N., 1986. Characteristics of maximum-value composite images from temporal AVHRR data. Int. J. Remote Sensing 7, 1417-1434.
Ji, L., Peters, A.J., 2003. Assessing vegetation response to drought in the northern Great Plains using vegetation and drought indices. Remote Sensing Environ. 87, 85-98.

Li, L., Chen, X., Wang, Z., Xu, W., Tang, H., 2010. Climate change and its regional differences over the Tibetan Plateau. Adv. Climate Change Res. 6, 181-186.

Liu, G., Liu, H., Yin, Y., 2013. Global patterns of NDVI-indicated vegetation extremes and their sensitivity to climate extremes. Environ. Res. Lett. 8, 025009.

Liu, X., Zhu, X., Zhu, W., Pan, Y., Zhang, C., Zhang, D., 2014. Changes in spring phenology in the Three-Rivers headwater region from 1999 to 2013. Remote Sensing 6, 9130-9144.

Lucht, W., Prentice, I.C., Myneni, R.B., Sitch, S., Friedlingstein, P., Cramer, W., Bousquet, P., Buermann, W., Smith, B., 2002. Climatic control of the highlatitude vegetation greening trend and Pinatubo effect. Science 296, $1687-$ 1689.

Ma, Y., Huang, Y., Chen, X., Li, Y., Bao, A., 2013. Modelling snowmelt runoff under climate change scenarios in an ungauged mountainous watershed, Northwest China. Math. Probl. Eng. 2013, 1-9.

Mao, J., Shi, X., Thornton, P.E., Piao, S., Wang, X., 2012. Causes of spring vegetation growth trends in the northern mid-high latitudes from 1982 to 2004. Environ. Res. Lett. 7, 014010.

McMahon, S.M., Parker, G.G., Miller, D.R., 2010. Evidence for a recent increase in forest growth. Proc. Natl. Acad. Sci USA 107, 3611-3615.

Myneni, R.B., Keeling, C.D., Tucker, C.J., Asrar, G., Nemani, R.R., 1997. Increased plant growth in the northern high latitude from 1981 to 1991. Nature 386, 698-702.

Peng, S., Chen, A., Xu, L., Cao, C., Fang, J., Myneni, R.B., Pinzon, J.E., Tucker, C.J., Piao, S., 2011. Recent change of vegetation growth trend in China. Environ. Res. Lett. 6, 044027.

Piao, S., 2003. Interannual variations of monthly and seasonal normalized difference vegetation index (NDVI) in China from 1982 to 1999. J. Geophys. Res., 108

Piao, S., Ciais, P., Huang, Y., Shen, Z., Peng, S., Li, J., Zhou, L., Liu, H., Ma, Y., Ding, Y., Friedlingstein, P., Liu, C., Tan, K., Yu, Y., Zhang, T., Fang, J., 2010. The impacts of climate change on water resources and agriculture in China. Nature 467, 43-51.

Piao, S., Cui, M., Chen, A., Wang, X., Ciais, P., Liu, J., Tang, Y., 2011. Altitude and temperature dependence of change in the spring vegetation green-up date from 1982 to 2006 in the Qinghai-Xizang Plateau. Agric. For. Meteorol. 151, 15991608 .

Piao, S., Friedlingstein, P., Ciais, P., Zhou, L., Chen, A., 2006a. Effect of climate and $\mathrm{CO}_{2}$ changes on the greening of the Northern Hemisphere over the past two decades. Geophys. Res. Lett. 33.

Piao, S., Mohammat, A., Fang, J., Cai, O. Feng, J., 2006b. NDVI-based increase in growth of temperate grasslands and its responses to climate changes in China. Global Environ. Change 16, 340-348.

Piao, S., Nan, H., Huntingford, C., Ciais, P., Friedlingstein, P., Sitch, S., Peng, S., Ahlstrom, A., Canadell, J.G., Cong, N., Levis, S., Levy, P.E., Liu, L., Lomas, M.R., Mao, J., Myneni, R.B., Peylin, P., Poulter, B., Shi, X., Yin, G., Viovy, N., Wang, T., Wang, X., Zaehle, S., Zeng, N., Zeng, Z., Chen, A., 2014. Evidence for a weakening relationship between interannual temperature variability and northern vegetation activity. Nat. Commun. 5, 5018.

Reichstein, M., Bahn, M., Ciais, P., Frank, D., Mahecha, M.D., Seneviratne, S.I., Zscheischler, J., Beer, C., Buchmann, N., Frank, D.C., Papale, D., Rammig, A., Smith, P., Thonicke, K., van der Velde, M., Vicca, S., Walz, A., Wattenbach, M., 2013. Climate extremes and the carbon cycle. Nature 500, 287-295.

Sun, J., Cheng, G., Li, W., Sha, Y., Yang, Y., 2013. On the variation of NDVI with the principal climatic elements in the Tibetan Plateau. Remote Sensing 5, 18941911.

Tan, Z., 2011. The Calculation and Simulation of Chinese North-South Demarcation based on GIS. Lanzhou University, Lanzhou.

Trenberth, K.E., Jones, P.D., Ambenje, P., Bojariu, R., Easterling, D., Klein Tank, A., Parker, D., Rahimzadeh, F., Renwick, J.A., Rusticucci, M., Soden, B., Zhai, P., 2007. Observations: Surface and Atmospheric Climate Change. Climate Change 2007: The Physical Science Basis.

Tucker, C., Pinzon, J., Brown, M., Slayback, D., Pak, E., Mahoney, R., Vermote, E., El Saleous, N., 2005. An extended AVHRR 8-km NDVI dataset compatible with MODIS and SPOT vegetation NDVI data. Int. J. Remote Sensing 26, 4485-4498.

Vu, M.T., Raghavan, S.V., Liong, S.Y., 2012. SWAT use of gridded observations for simulating runoff - a Vietnam river basin study. Hydrol. Earth Syst. Sci. 16, 2801-2811.

Wang, J., Li, H., Hao, X., 2010. Responses of snowmelt runoff to climatic change in an inland river basin, Northwestern China, over the past 50 years. Hydrol. Earth Syst. Sci. 14, 1979-1987.

Wang, J., Rich, P.M., Price, K.P., 2003. Temporal responses of NDVI to precipitation and temperature in the central Great Plains, USA. Int. J. Remote Sensing 24, 2345-2364

Wu, X., Liu, H., 2013. Consistent shifts in spring vegetation green-up date across temperate biomes in China, 1982-2006. Global Change Biol. 19, 870-880.

Wu, Z., Dijkstra, P., Koch, G.W., Hungate, B.A., 2012. Biogeochemical and ecological feedbacks in grassland responses to warming. Nat. Climate Change 2, 458-461.

Xu, G., Zhang, H., Chen, B., Zhang, H., Innes, J., Wang, G., Yan, J., Zheng, Y., Zhu, Z. Myneni, R., 2014. Changes in vegetation growth dynamics and relations with climate over China's Landmass from 1982 to 2011. Remote Sensing 6, 32633283.

Xu, W., Liu, X., 2007. Response of vegetation in the Qinghai-Tibet Plateau to global warming. Chinese Geogr. Sci. 17, 151-159.

Xu, X., Piao, S., Wang, X., Chen, A., Ciais, P., Myneni, R.B., 2012. Spatio-temporal patterns of the area experiencing negative vegetation growth anomalies in China over the last three decades. Environ. Res. Lett. 7, 1-9. 
Zhang, L., Guo, H., Ji, L., Lei, L., Wang, C., Yan, D., Li, B., Li, J., 2013. Vegetation greenness trend (2000-2009) and the climate controls in the Qinghai-Tibetan Plateau. J. Appl. Remote Sensing 7, 073572.

Zhao, X., Tan, K., Zhao, S., Fang, J., 2011. Changing climate affects vegetation growth in the arid region of the northwestern China. J. Arid Environ. 75, 946-952.
Zhou, L., Kaufmann, R.K., Tian, Y., Myneni, R.B., Tucker, C.J., 2003. Relation between interannual variations in satellite measures of northern forest greenness and climate between. J. Geophys. Res. 1982 and 1999, 108.

Zhou, L., Tucker, C.J., Kaufmann, R.K., Slayback, D., Shabanov, N.V., Myneni, R.B., 2001. Variations in northern vegetation activity inferred from satellite data of vegetation index during 1981-1999. J. Geophys. Res. 106, 20069. 